\title{
Evidence for the presence of Rhamphorhynchus (Pterosauria: Rhamphorhynchinae) in the Kimmeridge Clay of the UK
}

MichaelO'Sullivan, David M.Martill

\begin{abstract}
The second pterosaur genus to be established, Rhamphorhynchus von Meyer, 1847, has historically been used as a wastebasket material. Several species have been erected for fossils found in Europe and Africa, the majority of which are based on non-diagnostic material. Following Bennett's (1996) review of its taxonomy, Rhamphorhynchus is generally regarded as a monospecific taxon restricted to the Late Kimmeridgian and Tithonian of Southern Germany. Here we describe a disarticulated but complete right pterosaur wing, MJML K-1597 from the Kimmeridge Clay Formation of England. Based on a combination of morphology and statistical analysis, MJML K-1597 can safely be referred to Rhamphorhynchus, making it the first diagnostic Rhamphorhynchus specimen from outside of Germany. Furthermore, based on the unique length ratio between wing phalanx 1 and wing phalanx 2, MJML K-1597 can be referred to a new species of Rhamphorhynchus.
\end{abstract}

\section{Introduction}

Rhamphorhynchus muensteri von Meyer, 1847 is a medium sized piscivorous pterosaur with a prowed lower jaw and procumbent, fang-like teeth from Late Jurassic Plattenkalks of Southern Germany (Wellnhofer, 1975; Witton, 2013). Münster (1830) was first to discuss the specimen that eventually became the holotype, a skull preserved in dorsal view with an associated lower jaw (Wellnhofer, 1975). It was formally described by Goldfuss (1831), who named it Ornithocephalus muensteri Goldfuss, 1831. This holotype was destroyed in the Allied bombing of Berlin during World War II but numerous plastotypes exist and are accessioned in institutions across the world (e.g. NHMUK PV R 231). Münster (1839) described a more complete animal which he identified as a new species based on its extremely long tail, naming it Ornithocephalus longicaudus Münster, 1839 (Wellnhofer, 1975). von Meyer (1846) considered the long tailed pterosaurs of the Late Jurassic Plattenkalks to be distinct from Pterodactylus Cuvier, 1809, placing them in the subgenus Pterodactylus(Rhamphorhynchus), which was given generic status a year later (von Meyer, 1847) with $R$. muensteri made the type species. Subsequently, Rhamphorhynchus became the most speciose pterosaur genus after Pterodactylus. By 1975 dozens of species of Rhamphorhynchus had been erected and/or synonymised (Wellnhofer, 1975), with most based on isolated or non-diagnostic material (e.g. Sauvage, 1873). Wellnhofer (1975) performed a major re-evaluation of the taxonomic content of Rhamphorhynchus and reduced its species count to 5. Bennett (1995) carried out a second major revision in which he argued that several characters Wellnhofer (1975) considered to be specific were a 
combination of ontogenetic, sexual and individual variation. Bennett (1995) synonymised all German species of Rhamphorhynchus into the type species, R. muensteri. With regard to Rhamphorhynchus species erected on material from outside of Germany, Bennett (1995) briefly mentioned they were most likely indeterminate rhamphorhynchids but a more detailed evaluation was considered beyond the scope of his study.

While Bennett (1995) did not discuss non-German examples of Rhamphorhynchus in detail, he is most likely correct that previously identified non-German material is indeterminate (see below), making Rhamphorhynchus an exclusively German taxon. However in recent years, some Late Jurassic pterosaur collections have become available which may include non-German examples of Rhamphorhynchus. The Etches Collection (MJMLK) of fossils from the Kimmeridge Clay Formation of Dorset, England, houses numerous examples of plesiosaurs, crocodiles and other reptiles; including several pterosaurs. These consist primarily of appendicular fossils with some well-preserved axial specimens, including the skull of the Late Jurassic wukongopterid Cuspicephalus scarfi Martill and Etches, 2013 (Witton et al., 2015). Apart from Cuspicephalus and several appendicular, the majority of the material appears to be to rhamphorhynchine. Due to the isolated nature of the fossils, identifying them to a higher taxonomic level is problematic. One exception is MJML K-1597, a complete disarticulated wing preserved on a slab of Kimmeridge Clay. Here we describe MJML K-1597, and make a case for assigning it to Rhamphorhynchus. Institutional Abbreviations: BMNHC, Beijing Museum of Natural History, Beijing, China; MB.R, Humboldt University Museum, Berlin, Germany; NHMUK, Natural History Museum UK, London, United Kingdom; MJML K, The Etches Collection, Kimmeridge, Dorset, UK; TM, Teylers Museum, Haarlem, The Netherlands.

\section{Non-German pterosaurs previously identified as Rhamphorhynchus}

Fossils referred to Rhamphorhynchus have been found in Africa, Portugal, Asia and the United Kingdom (Bennett, 1995; Jain, 1974; Barrett et al., 2008). The Late Jurassic Tendaguru Formation of Mtwara, Tanzania has yielded several indeterminate pterosaur specimens (Janensch, 1914; Parkinson, 1930; Unwin and Heinrich, 1999), and an incomplete distal right radius and ulna (MB.R. 2845) identified as the new species, Rhamphorhynchus tendagurensis Reck, 1931. This specimen was re-evaluated by Unwin and Heinrich (1999) who concluded that while the bones could be identified as a non-pterodactyloid pterosaur based on the morphology of the distal articulation of the radius and ulna, it differed from the condition seen in Rhamphorhynchus and lacks diagnostic features of the genus. Unwin and Heinrich (1999) concluded it was an indeterminate non-pterodactyloid and treated $R$. tendagurensis as a nomen dubium. Jain (1974) described a partial jaw he identified as a new species of Campylognathoides Strand, 1928. Barrett et al. (2008) refer the specimen to Rhamphorhynchus sp. while Padian (2008b) believes it to be a fish. Colbert (1969) discussed an anonymous account of possible Rhamphorhynchusmaterial from "Soviet Asia" without mentioning the nature of the remains. Thulborn (1973) and Malafaia et al. (2010) figure pterosaur teeth 
from Pombal, Portugal, which are similar to those of Rhamphorhynchus but due to the lack of diagnostic characters are identified as indeterminate pterosaurs.

The United Kingdom is far more productive than the rest of Europe for Jurassic pterosaurs and subsequently several specimens have been referred to Rhamphorhynchus in the last 200 years. Huxley (1859) described 3 jaws from the "Stonesfield Slate" (now called the Taynton Limestone Formation, Boneham and Wyatt, 1993) of Oxford which he identified as representing two new species, Rhamphorhynchus bucklandi Huxley, 1859 and Rhamphorhynchus depressirostris Huxley, 1859. Seeley (1880) described the new Stonesfield taxon Rhamphocephalus prestwichi Seeley, 1880 and suggested that all Stonesfield pterosaur material could be placed in Rhamphocephalus. Lydekker (1888) formalised this suggestion, assigning both $R$. depressirostris and $R$. bucklandi to Rhamphocephalus while retaining the individual species names. von Arthaber (1922)suggested that Rhamphocephalus was a junior synonym of Rhamphorhynchus, but subsequent authors did not accept this recommendation. Lydekker (1890) described several associated pterosaur elements from the Callovian-Oxfordian Oxford Clay Formation of Huntingdonshire consisting of the glenoidal region of the pelvis, a broken femur and disarticulated vertebrae. He identified the remains as a new species, Rhamphorhynchus jessoniLydekker, 1890 , as he considered the pelvis to be diagnostic for the genus. This specimen is currently in review but preliminary results suggest that it lacks autapomorphic features of Rhamphorhynchus. Lydekker (1891) described several specimens from the Late Jurassic Kimmeridge Clay Formation of Weymouth, Dorset, including two isolated quadrates with similar morphologies and a marked difference in size. Lydekker (1891) considered these quadrates pterosaurian and assigned the larger specimen to the French species Pterodactylus suprajurensis Sauvage, 1873, and the smaller to another Kimmeridge Clay pterosaur, Pterodactylus manseli Owen, 1874. He argued that based on size, none of these taxa could be aligned to Pterodactylus and recommended all British Kimmeridgian examples of Pterodactylus be made species of Rhamphorhynchus. The holotypes of Pt. manseli and Pt. pleydelli are both proximal humeri (Owen, 1874) possessing deltopectoral crests (DPC) positioned well below the proximal margin of the humerus with somewhat constricted DPC bases, features found in several rhamphorhynchines (Colbert, 1969; Wellnhofer, 1975; Hone et al., 2012; Lü et al., 2012). Owen (1874) also figured several first wing phalanges (WP1) assigned to both species with strongly developed grooves along their posterior margins, a feature common in rhamphorhynchines (see below). These specimens can be placed in Rhamphorhynchinae but a more detailed analysis is needed to identify them generically. The material is currently being studied as part of a larger review and will be described elsewhere. The quadrates described by Lydekker (1891) on the other hand are only superficially similar to pterosaur quadrates but are very similar to the quadrates of coelacanth fish (Forey, 1997), and are considered such here. Etches and Clarke (2010) figure several limb elements from the Kimmeridge Clay Formation which they identify as Rhamphorhynchus sp. These specimens are currently under review and will be described in due course. 


\section{Locality and geological setting}

MJML K-1597 was collected from the foreshore by Mr Steve Etches from shales of the Pectinatus Zone of the Upper Kimmeridge Clay Formation (Ogg, 2004) at Encombe, Dorset in December of 2002 (National Grid Reference SY 944773, Figs. 1 and 2). The Pectinatus Zone represents bed numbers KC46-49 of Wright and Cox (2001). KC46-49 consists of organic-rich finely laminated mudstones, interbedded with both fissile and bituminous mudstones, shelly oil shale and coccolith rich laminated limestones (Gallois, 2000). The strata here are moderately undisturbed with a gentle north easterly dip of a degree or two, but fracturing of the mudstone can be heavy in places.

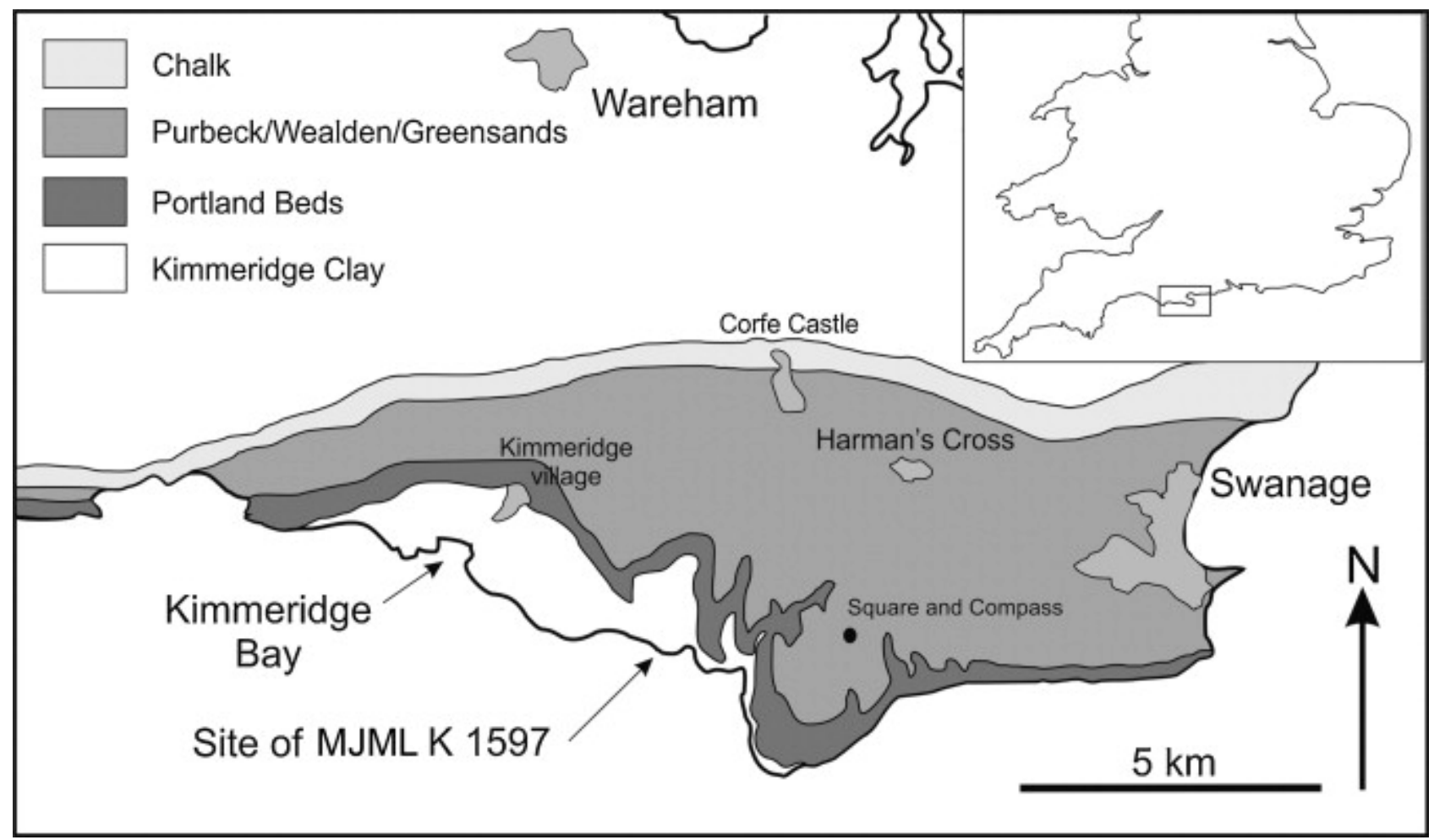

Figure 1: Simplified geological map of the Kimmeridge area showing the distribution of strata and where MJML K-1597 was collected from.

Modified from Martill and Etches (2013). 


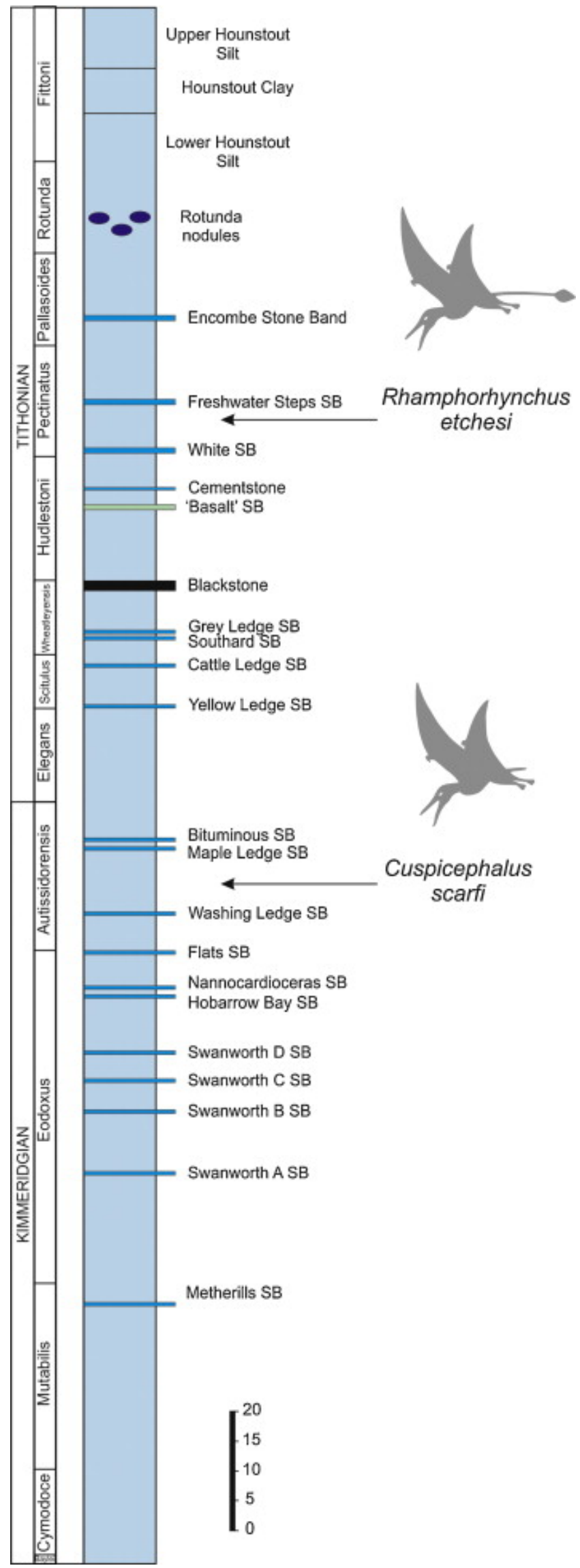

Figure 2: Stratigraphic column of the Kimmeridge Clay Formation of Encombe, Dorset, United Kingdom showing the levels Cuspicephalus scarfi and Rhamphorhynchus etchesi (MJML K-1597) were extracted from.

Modified from Gallois (2004). Scale $=20 \mathrm{~m}$. 


\section{Materials and methods}

MJML K-1597 (Fig. 3) is a disarticulated almost complete right pterosaur forelimb with associated elements from the left wing. The bones lie in a single plane on a slab measuring $403 \mathrm{~mm} \times 487 \mathrm{~mm}$. To test the placement of MJML K-1597 within basal pterosaurs, several bivariate analyses were produced which compared the ratios of one bone with that which preceded it. The analyses were performed on the generic level with one exception (see below) and included the following material: 54 specimens of Rhamphorhynchus, 17 specimens of Dorygnathus Wagner, 1860, 6 specimens of Campylognathoides; 5 specimens of Wukongopteridae (consisting of a combination of Darwinopterus Lü et al., 2010, Wukongopterus Wang et al., 2009, Kunpengopterus Wang et al., 2010 and Changchengopterus Lü, 2009) and 4 specimens of Scaphognathus Wagner, 1861. The wukongopterids were not divided into individual genera as the taxa are distinguished from each other primarily on skull characters which are not relevant to this study. The data was taken from the following sources: Wellnhofer (1975), Padian (2008a, 2008b), Lü et al. (2010, 2011), Wang et al. $(2009,2010)$, Bennett (2014) and Li et al. (2014). The graphs and specimen numbers of the material used can be found in the supplementary data. Due to some of the reference material lacking measurements and the need to compensate for the absolute size-dependency of the data distribution, the data is presented as ratios relative to the shortest element in the wing (metacarpal IV, MCIV). The syncarpal is excluded from the analyses as its dimensions are not included in the majority of sources.

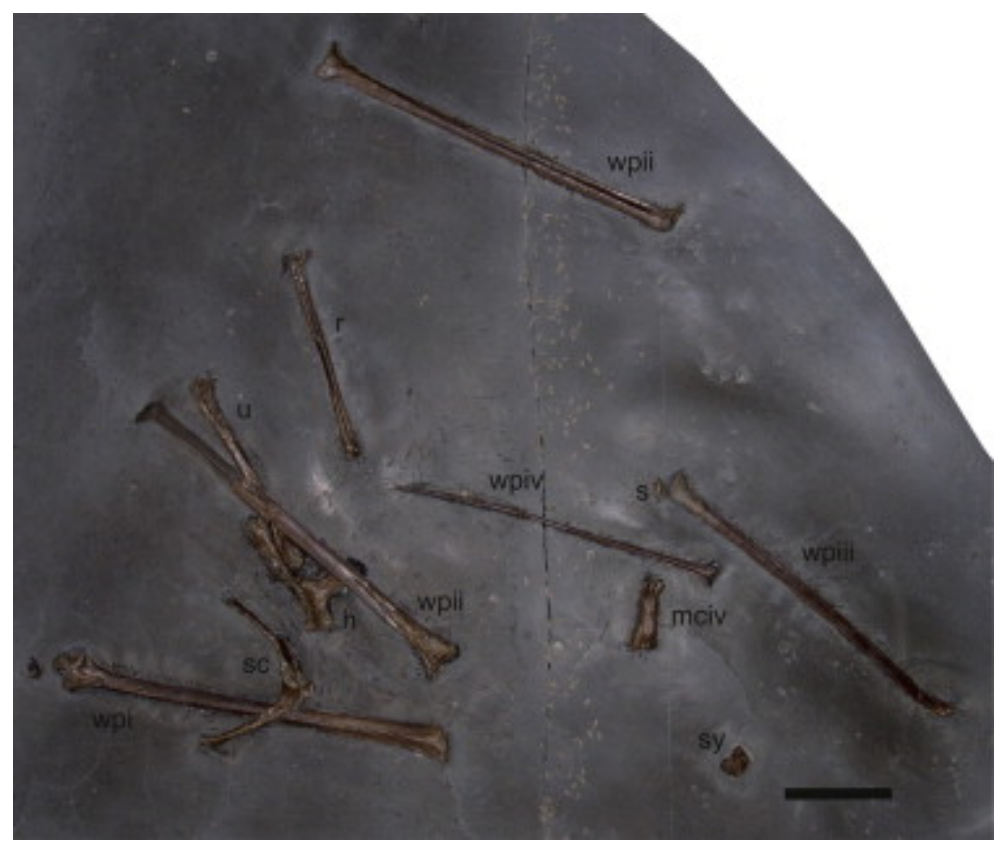

Figure 3: MJML K-1597, associated of right and left wing elements from the rhamphorhynchid pterosaur Rhamphorhynchus etchesi sp. nov. Abbreviations: h, humerus; mciv, metacarpal IV; r, radius; s, sesamoid; sc, scapulocoracoid; sy, syncarpal; u, ulna; wpi-iv, wing phalanx I-IV. Scale $=50 \mathrm{~mm}$. 
Some confusion currently exists over the content of the Rhamphorhynchidae

(Rhamphorhynchinae + Scaphognathinae). Kellner (2003) defines Rhamphorhynchidae as "all pterosaurs closer to Rhamphorhynchus", but the characters used for the group are interchangeable with the definition of Rhamphorhynchus (sensu Bennett, 1995). Unwin (2003) provides a more detailed diagnosis with distinct characters supporting the clade and its sub-units. Lü et al. (2010) finds a more poorly resolved Rhamphorhynchidae but a monophyletic Rhamphorhynchinae, though it now includes Cacibupteryx Gasparini et al., 2004 (usually recovered as a scaphognathine). Andres and Myers (2013) present a Rhamphorhynchidae similar to Unwin (2003) but which excludes Sordes Sharov, 1971 and Parapsicephalus von Arthaber, 1919, as well as including Cacibupteryx in Rhamphorhynchinae. This is somewhat problematic as a recent study suggests that Parapsicephalus is a true rhamphorhynchine (O'Sullivan, 2013). Bennett (2014) suggests that one of the best-known rhamphorhynchine taxa, Dorygnathus, may be a scaphognathine. Presently the phylogeny of basal pterosaurs is more poorly resolved than that of monofenestratans. For the purposes of this review the authors use the phylogeny of Unwin (2003) as this appears to be one of the best supported analyses and its results correspond with the authors' own observations.

\section{Systematic palaeontology}

Pterosauria Kaup, 1834

Rhamphorhynchidae Seeley, 1870

Rhamphorhynchinae von Nopcsa, 1928

Genus Rhamphorhynchus von Meyer, 1847

Type species - Pterodactylus longicaudus Münster, 1839

Type specimen. TM 6924, articulated, near-complete pterosaur skeleton (Münster 1839, Wellnhofer, 1975)

Revised diagnosis - As defined in Bennett (1995) with the removal of the 6th character: First wing phalanx is longest and roughly the length of the skull.

5.1. R. muensteri von Meyer, 1847 (Goldfuss, 1831; Münster, 1839; von Meyer, 1846)

Holotype - The type of R. muensteri was lost during WWII. A neotype has never been erected due to the prevalence of high quality casts in various institutions (e.g. NHMUK PV R 231). 
Occurrence - Nusplingen Limestone (Late Jurassic, Tithonian, Klug et al., 2005) of Wüttemburg and Solnhofen Limestone (Late Jurassic, Tithonian, Frey et al., 2011) of Solnhofen, both in Southern Germany.

Emended diagnosis - As for Rhamphorhynchus with the inclusion of the character first wing phalanx is longest in the wing.

\subsection{Rhamphorhynchus etchesi sp. nov.}

Holotype - MJML K-1597, associated elements from a left and right wing.

Occurrence - Kimmeridge Clay (Late Jurassic, Tithonian) of Kimmeridge, United Kingdom.

Etymology - Species name etchesi in honour of Mr. Steve Etches, one of the most prolific Jurassic fossil collectors in England and collections manager of MJML K.

Diagnosis - MJML K-1597 is identified as Rhamphorhynchus on a combination of the morphology of its scapulocoracoid and the structure of the wing (see below). It is diagnosed as a new species based on the second wing phalanx being the longest phalanx in the wing.

\subsection{Description}

MJML K-1597 is a partial right pterosaur forelimb with associated left wing elements (Fig. 3, Table 1). The right wing is disarticulated but all elements are in association. The bones lie on a slab of Kimmeridge Clay. The slab has been reassembled, as evidenced by a large split passing through two of the phalanges close to the centre of the rock. All elements are at least partially three-dimensional. The long bones are crushed at their epiphyses but maintain three-dimensional diaphyses. 
Table 1. Table of measurements for MJML K-1597.

$\begin{array}{ll}\text { Element } & \mathbf{m m} \\ \text { Scapula } & 40 \\ \text { Coracoid } & 41 \\ \text { Humerus } & 60 \\ \text { DPC (proximodistally) } & \sim 10 \\ \text { DPC (anteroposteriorly) } & \sim 10 \\ \text { Medial crest (anteroposteriorly) } & 4 \\ \text { Radius } & 97 \\ \text { Ulna } & 97 \\ \text { MCIV } & 33 \\ \text { Syncarpal (anteroposteriorly) } & 13 \\ \text { WP1 } & 171 \\ \text { WP2 } & 175 \\ \text { WP3 } & 163 \\ \text { WP4 } & 152\end{array}$

Scapulocoracoid: There is a single three-dimensional right scapulocoracoid on MJML K-1597 (Fig. 4). It is exposed in lateral view as evidenced by the exposed glenoid. Both the coracoid and scapula are complete although slightly worn and fractured proximal to the glenoid. The glenoid is fractured but mostly whole, but both the supraglenoidal buttress (SGB) and lower glenoidal tubercle (LGT) are broken at their tips. The scapula is $40 \mathrm{~mm}$ long, $7 \mathrm{~mm}$ wide at the glenoid, approximately $2 \mathrm{~mm}$ wide at its proximal termination and $3 \mathrm{~mm}$ wide medially. It is bowed $150^{\circ}$ relative to the posterolateral margin of the glenoid. The coracoid is $41 \mathrm{~mm}$ long, $6 \mathrm{~mm}$ wide around the glenoid, $4 \mathrm{~mm}$ wide at its proximal termination and $3 \mathrm{~mm}$ medially. Together the scapula and coracoid form an angle of approximately $65-70^{\circ}$, giving the scapulocoracoid a Vshape in lateral view. The elements are fully fused and there is no identifiable suture between them. The scapula is relatively simple with the exception of the scapular process, a low semi-circular process synonymous with the posterior process of Eck et al. (2011). It extends $5 \mathrm{~mm}$ along the length of the scapula, $1 \mathrm{~mm}$ in front of it and may be homologous to the acromion process found in several other groups (Padian, 1983; Nesbitt, 2011). The acrocoracoid process is a rounded sub-trapezoidal process with muscle scars, possibly from the $m$. supracoracoideus (Jensen and Padian, 1989; Bennett, 2003). It extends $5 \mathrm{~mm}$ in front of the glenoid, is $7 \mathrm{~mm}$ wide dorsoventrally at its base and $4 \mathrm{~mm}$ wide at its tip. The biceps tubercle is similar to the scapular process although it is more robust. It extends $5 \mathrm{~mm}$ along the coracoid shaft and $1.5 \mathrm{~mm}$ below it. The sternocoracoidal joint is a well-developed suboval extension of the proximal coracoid. It comprises $4 \mathrm{~mm}$ of the proximal coracoid and extends $2 \mathrm{~mm}$ above its dorsal margin. The glenoid 
boundaries are defined by the SGB and the LGT. It is $13 \mathrm{~mm}$ tall with the SGB being 5-6 $\mathrm{mm}$ tall and the LGT is $7-8 \mathrm{~mm}$ tall. Given the preservation, the dorsoventral width of the SGB is difficult to determine but the LGT is approximately $4 \mathrm{~mm}$ wide and angled obliquely relative to the SGB.

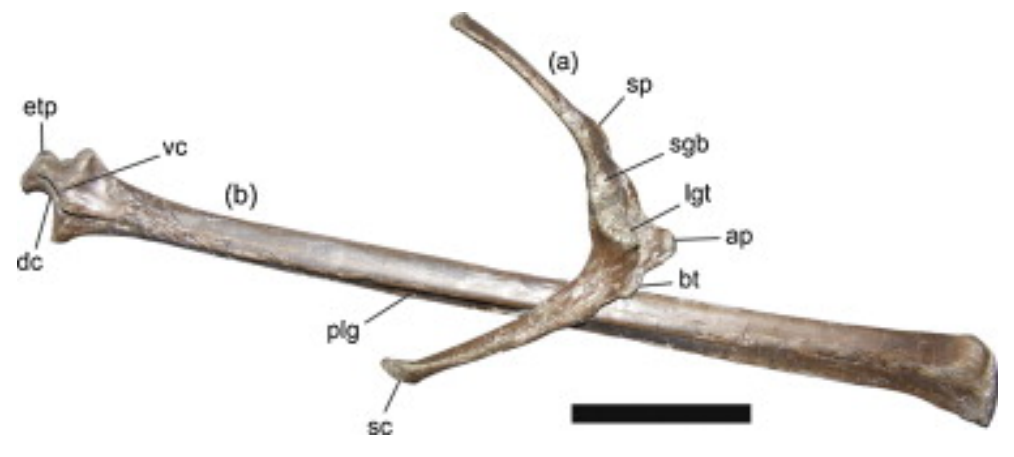

Figure 4: The (a) right scapulocoracoid in lateral view, and (b) left WP1 in ventral view of MJML K-1597. Abbreviations: ap, acrocoracoid process; bt, biceps tubercle; dc, dorsal cotyle; etp, extensor tendon process; lgt, lower glenoidal tubercle; plg, posterior longitudinal groove; sc, sternocoracoidal joint; sgb, supraglenoidal buttress; $\mathrm{sp}$, scapular process. Scale $=25 \mathrm{~mm}$.

Humerus: Only the right humerus (Fig. 5) is preserved lying adjacent to the scapulocoracoid. It overlies the ulna and is itself overlain by a WP2 (Fig. 6). The bone is crushed and abraded but otherwise intact. The humerus is $60 \mathrm{~mm}$ long with a diaphysis $6 \mathrm{~mm}$ wide proximal to the humeral head and $10 \mathrm{~mm}$ wide distally. It is preserved in ventral view as evidenced by the rugosity visible on the posterior medial crest, the slightly dished appearance of the articular surface of the humeral caput and the keeled side of the triangular diaphysis facing outwards. The diaphysis has a $160^{\circ}$ curvature relative to the posterior margin of the humeral head. The maximum humeral length/width ratio (based on length divided by the thinnest point of the diaphysis) is 10. Despite heavy crushing the entepicondyle, trochlea, capitulum and part of the ectepicondyle are all identifiable. The medial crest is a triangular process extending $4 \mathrm{~mm}$ off of the posterior side of the humeral head. The deltopectoral crest (DPC) is strongly deflected beneath the proximal margin of the humerus. The anterior termination of the DPC is overlain by a WP2, giving the DPC a minimum length of $10 \mathrm{~mm}$. It is $10 \mathrm{~mm}$ wide proximal to the body of the humerus, pinching medially to $7 \mathrm{~mm}$ wide before expanding again to $9 \mathrm{~mm}$. 


$$
\text { I }
$$


Radius and Ulna: MJML K-1597 preserves an associated radius and ulna towards the centre of the slab (Fig. 6). The radius is unobscured but the ulna is partially covered by a WP2 and the humerus. Both bones are $97 \mathrm{~mm}$ long. The radius is $10 \mathrm{~mm}$ wide proximally, $7 \mathrm{~mm}$ wide distally and $3 \mathrm{~mm}$ wide medially. The ulna is $10 \mathrm{~mm}$ wide distally, around $11 \mathrm{~mm}$ wide proximally and 5-7 mm wide medially. Both bones have crushed epiphyses with three-dimensional diaphyses. Which wing the elements are from is difficult to determine due to the crushing and obscuring of their epiphyses, the most diagnostic elements for determining left and right. The distal end of the radius is heavily damaged with very little detailed morphology visible. The proximal end is similarly crushed but does exhibit an enlarged process extending away from the diaphysis giving it a slight L-shaped appearance. At the tip of this process is a slight rugosity that has not been noted in most other studies on basal pterosaurs (e.g. Wellnhofer, 1975; Andres et al., 2010) but is figured by Bennett (2001) in his osteological description of Pteranodon Marsh, 1876 where he notes its presence on the posterior side of the proximal tubercle. Its presence here suggests the bone is a right radius seen in posterior view. The broadest end of the ulna is the proximal end (Wellnhofer, 1975, 1991; Padian, 2008a) and here this is the epiphysis closest to the right humerus. This orientation suggests that it can be identified as the right ulna.

Syncarpal and sesamoid: A single fully fused syncarpal is preserved on MJML K-1597 (Fig. 7) that is $10 \mathrm{~mm}$ dorsoventrally and $13 \mathrm{~mm}$ anterioposteriorly. It is identified as a right distal syncarpal in proximal view due to its more curved anterior margin. The dorsal articular surface has an intact, curved and slightly irregular dorsal margin. A well-developed semi-ovate cotyle takes up approximately $50 \%$ of the visible surface area of the syncarpal. There is a prominent ridge extending along its anterior margin with a second, lesser ridge separates the dorsal and ventral articular surfaces. This second ridge is broad and sigmoidal throughout its dorsoventral length. Near the dorsal termination of the ridge there is an irregular surface which may correspond to the fovea figured by Bennett (2001) for Pteranodon. The ventral articular surface may have only been partially preserved, but what can be seen suggests it is similar to the dorsal. A possible articulation for the preaxial carpal is seen on the anterior margin but as previously mentioned, it is unclear if this is the total articular surface or if it is partially obscured. There is a single indeterminate sesamoid preserved in proximity to the WP3 (Figs. 3 and 7). This bone is strongly ovoid and has a slightly rugose surface texture. Unfortunately there is little information to identify it. It is similar to the Sesamoid B figured by Bennett (2001) but is here considered indeterminate. 


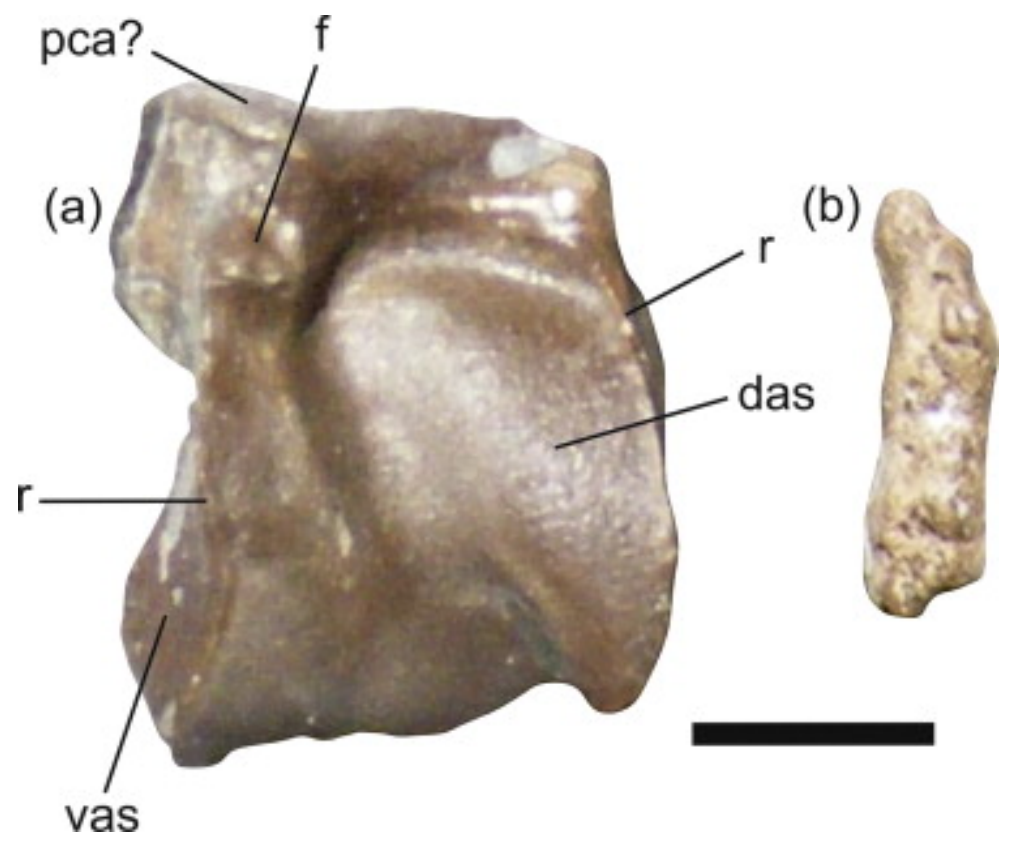

Figure 7: The (a) right distal syncarpal in proximal view and (b) the isolated sesamoid. Abbreviations: das, dorsal articular surface; $f$, fovea; pca, preaxial carpal articulation; $r$, ridge. Scale $=5 \mathrm{~mm}$.

Metacarpal IV: There is a single MCIV preserved (Fig. 8) near the WP3 and WP4. It is $33 \mathrm{~mm}$ long, $9 \mathrm{~mm}$ wide proximally, $14 \mathrm{~mm}$ wide distally and $8 \mathrm{~mm}$ wide medially. The diaphysis is cracked and damaged in places but is otherwise in good condition. There is a sub-rectangular dorsal process lying against the matrix which is possibly a fragment of the crista metacarpi flipped up, which when combined with the distal condyles extending into the matrix identifies it as a right MCIV in anterior view. The proximal margin of the MCIV is divided into three regions. The dorsal tuberosity is a sub-triangular process which defines the proximodorsal margin of the articulation. The medial tuberosity is sub-rectangular and fully threedimensional with a dished anterior surface. The ventral crest is sub-triangular but it is rounder and wider than the dorsal tuberosity with a ventral margin that gently curls anteriorly. The entire proximal section of the MCIV shows well developed muscle scars, particularly along the ventral crest. In the centre of the diaphysis, there is a small process positioned just dorsal to the centre of the diaphysis. It is $3 \mathrm{~mm}$ long and $1 \mathrm{~mm}$ deep. The identification of this process is indeterminate but it may have been an attachment point for metacarpals I-III or the intermetacarpal ligaments (Bennett, 2001). The distal articulation is formed by a robust bicondylar ginglymus. The condyles are separated by a broad sulcus, approximately $4 \mathrm{~mm}$ wide and with a scarred surface. The dorsal condyle is $7 \mathrm{~mm}$ long and $2.5 \mathrm{~mm}$ deep. The ventral condyle is approximately $9 \mathrm{~mm}$ long and $3 \mathrm{~mm}$ deep. It has a semicircular ventral margin absent in the dorsal condyle and is overall more robust. 


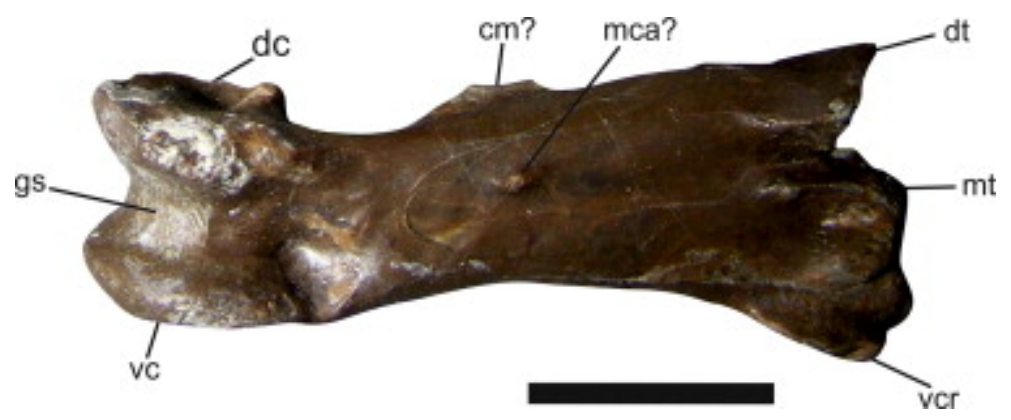

Figure 8: The right metacarpal IV in anterior view. Abbreviations: $\mathrm{cm}$, crista metacarpi; dc, dorsal condyle; $\mathrm{dt}$, dorsal tuberosity; gs, ginglymoid sulcus; mca, metacarpal 1-3 attachment; mt, medial tuberosity; vc, ventral condyle; vcr, ventral crest. Scale $=10 \mathrm{~mm}$.

Wing Phalanges: There are five phalanges preserved on MJML K-1597 which have undergone varying degrees of crushing and compaction. The WP2 (Fig. 6) positioned near the centre of the slab is missing approximately half its length but its distal end is preserved as an external mould. Several of the phalanges have a longitudinal groove (Figs. 4 and 9) running along the posterior margin of the phalanx. At first glance MJML K-1597 appears to have a complete right wing digit with a single associated left WP2. However upon closer inspection there is a slightly more mixed assemblage. The WP1 (Fig. 5) has a prominent ventral cotyle, as figured in several papers (e.g. Bennett, 2001; Andres et al., 2010), identifying this element as a left WP1. The WP2 at the top of the slab (Fig. 9) has a rugose surface on the distal epiphysis and a similar but less well developed rugosity on the proximal epiphysis. According to Bennett (2001), these rugosities are attachment points for the collateral ligament and are more strongly developed on the ventral side. This, combined with the visible posterior groove, identify it as a right WP2 preserved in ventral view and the broken WP2 is from the left wing. Only one WP3 is preserved on MJML K-1597 (Fig. 9). It can be identified as a right WP3 in ventral view through the position of the posterior groove. The isolated WP4 (Fig. 9) is identified as a right phalanx based on the prominent posterior groove and the raised cross-section to the shaft. The WP1 is $171 \mathrm{~mm}$ long, $18 \mathrm{~mm}$ wide proximally, $15 \mathrm{~mm}$ wide distally and $8 \mathrm{~mm}$ wide medially. It has a sub-rectangular extensor tendon process which is approximately $8 \mathrm{~mm}$ long proximodistally and $7 \mathrm{~mm}$ wide anteroposteriorly. It forms the anterior margin of the dorsal and ventral cotyles, making up around $50 \%$ of the latter. There is a triangular prominence on both the proximal and distal epiphyses. The proximal prominence forms the posterior margin of the cotyle and the distal prominence forms the posterior half of the articulation with the subsequent phalanx. Both of prominences are quite broad in comparison to the other phalanges and extend a short distance towards the midpoint of the diaphysis. Both WP2 are $175 \mathrm{~mm}$ long, $21 \mathrm{~mm}$ wide proximally, $14 \mathrm{~mm}$ distally and $8 \mathrm{~mm}$ wide medially. There is a well-developed triangular prominence on the posterior margins of both proximal and distal ends. The proximal prominence is thin and curves towards the articulation. Both elements can be identified as WP2 due to their somewhat deep cotyle with its sigmoidal proximal margin and well developed posterior "lip" formed by the curving triangular prominence and the relatively straight distal articulation with its rounded 
anterior margin. The single WP3 preserved in MJML K-1597 is $163 \mathrm{~mm}$ long, $12 \mathrm{~mm}$ wide proximally, $9 \mathrm{~mm}$ wide distally and $7 \mathrm{~mm}$ wide at their midpoint. The diaphysis shows the same mode of collapse as the left WP2, indicating the presence of a posterior groove. There is a triangular posterior prominence at the proximal articulation but unlike the prominence on WP2, the proximal margin is straighter and it has a broader distal extension. The distal articulation has an anterior margin which is less well developed and more inclined than in WP1 or WP2, giving it a more sloping appearance. Towards the distal articulation the diaphysis becomes slightly thinner and appears to curve posteriorly. There is a slight fracture at the bend, suggesting this may be a taphonomic artefact. WP4 is $152 \mathrm{~mm}$ long, $9 \mathrm{~mm}$ wide proximally, $1 \mathrm{~mm}$ wide distally and $2 \mathrm{~mm}$ wide medially. Its proximal epiphysis is similar to that of WP3 but its triangular prominence is shorter and broader. The bone thins steadily throughout its length, terminating to a point. Using the data provided in O'Sullivan et al. (2013), the wingspan is estimated to be $1.7 \mathrm{~m}$.

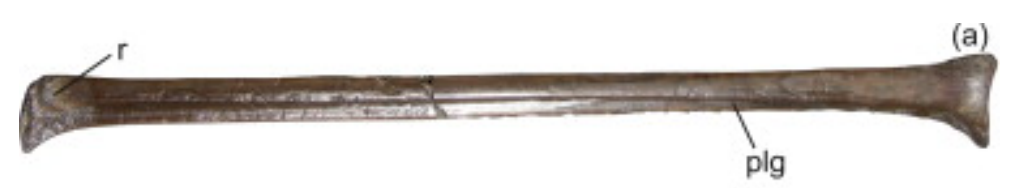

(b)

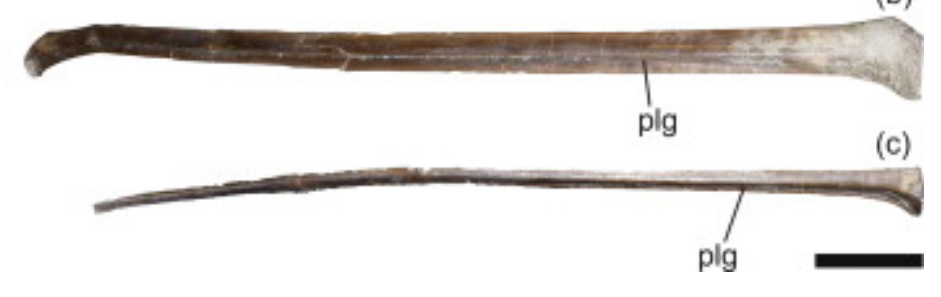

Figure 9: The (a) right WP2 (b) right WP3 and (c) right WP4, all in ventral view. Abbreviations: plg, posterior longitudinal groove; $r$, rugosity. Scale $=20 \mathrm{~mm}$.

Ontogeny: All elements of MJML K-1597 are well ossified and fully fused (i.e. the scapulocoracoid interface and the distal syncarpal). This combined with the animal's large size suggests that MJML K-1597 represents a mature adult (Bennett, 1995, 1996, 2001).

\section{Comparisons}

Rhamphorhynchus etchesi has the typical morphology of a pterosaur wing including an elongate scapula and coracoid, an enlarged deltopectoral crest on the humerus and hyper-elongated fourth digit. The glenoid is restricted to the scapula and the MCIV is short, characters common to non-pterodactyloid pterosaurs (Wellnhofer, 1978; Lü et al., 2010). The scapula in Dimorphodon has a similar curve to its proximal half but smaller glenoidal region (Buckland, 1829). The coracoid is shorter and straighter than in MJML K-1597 being around half the length of the scapula. In MJML K-1597 the coracoid is almost the same length as the scapula with a slight curve along its ventral margin. This coracoidal morphology also distinguishes it from Carniadactylus, Dalla Vecchia, 1995 and Campylognathoides, which possess morphologies distinct from Dimorphodon but with similarly short and robust coracoids (Padian, 2008b; 
Dalla Vecchia, 2009). On the other hand the scapulocoracoid compares well to those seen in more derived pterosaurs such as Dorygnathus, NHMUK PV R36634 (possibly an example of Parapsicephalus), Sericipterus Andres et al., 2010, Rhamphorhynchus and Darwinopterus. All share elongate scapulae and coracoids although details of the morphology can vary. Dorygnathus, Darwinopterus and NHMUK PV R36634 all possess straighter coracoid shafts (Padian, 2008a; O'Sullivan et al., 2013). NHMUK PV R36634 also has a much larger biceps tubercle. The coracoid of Sericipterus is very similar to MJML K-1597 but the scapula is more posteriorly inclined (Andres et al., 2010). The overall morphology is most similar to that of Rhamphorhynchus, with its elongate coracoid and slightly inclined scapula (Wellnhofer, 1975, 1991; Witton, 2013).

The humerus of MJML K-1597 is arguably the most informative element. With a length/width ratio of 10, it falls into the range of several non-pterodactyloid pterosaurs including Dimorphodon, Anurognathus Döderlein, 1923, Eudimorphodon Zambelli, 1973, Campylognathoides, Dorygnathus, and Rhamphorhynchus (O'Sullivan et al., 2013). In the majority of non-pterodactyloid pterosaurs (e.g. Buckland, 1829; Wellnhofer, 1978; Wild, 1978; Stecher, 2008; Padian, 2008b; Lü et al., 2010; Bennett, 2014), the DPC is positioned close to the proximal humeral margin whereas in MJML K-1597 it is deflected away from the head. The rhamphorhynchines Dorygnathus (Padian, 2008a), NHM PV R36634 (O'Sullivan et al., 2013), Sericipterus (Andres et al., 2010), Nesodactylus Colbert, 1969, Bellebrunnus Hone et al., 2012, Qinglongopterus Lü et al., 2012 and Rhamphorhynchus (Wellnhofer, 1975, 1991) all have distally deflected DPCs however the degree of deflection is highly variable. While Dorygnathus, Sericipterus and NHM PV R36634 are only slightly deflected, the other taxa can have a DPC displaced to a much greater degree ( $5 \mathrm{~mm}$ or more below the proximal margin). The degree of deflection seen in MJML K-1597 is similar to Nesodactylus and the Zittel Wing specimen of Rhamphorhynchus (Zittel, 1882) but the Zittel Wing, NHMUK 47002 and MJML K-1597 are more strongly deflected compared than Nesodactylus. Many rhamphorhynchine humeri have constrictions in the body of the DPC. In extreme cases this can form an axe-like structure (Unwin, 2003), the development of which is specifically and ontogenetically variable. The axe head is well developed in both Nesodactylus (Colbert, 1969) and Rhamphorhynchus (Wellnhofer, 1975). While the anterior DPC is obscured in MJML K-1597 it is in a similar position to that of Nesodactylus and the Zittel Wing (Zittel, 1882). The humeral shaft is more robust than that of Nesodactylus but similar to several examples of Rhamphorhynchus (Wellnhofer, 1975, 1991).

The radius, ulna and MCIV present little in the way of taxonomic information in MJML K-1597. The radius/ulna complex is poorly preserved relative to the other elements and in this case lacks diagnostic characters. The short, squat MCIV is typical of the morphology seen in non-pterodactyloids (Wellnhofer, 1991; Lü et al., 2010) but, in part due to the angle of preservation, it is difficult to identify any diagnostic characters. It is compares as well to the MCIV of Triassic pterosaurs (Dalla Vecchia and Cau, 2014) as it does 
to those from the Jurassic (Wellnhofer, 1991; Padian, 2008a, 2008b). The wing phalanges on the other hand do provide some useful information. The posterior margins of several phalanges possess posterior longitudinal grooves. Such grooves are common to rhamphorhynchine pterosaurs (Wellnhofer, 1991; Unwin, 2003) and appear to be absent in other groups. Within Rhamphorhynchinae, the only pterosaurs known with multiple complete wings are Dorygnathus and Rhamphorhynchus. In Dorygnathus the wingspan is 3-3.3 times the length of the wing digit while in Rhamphorhynchus the wingspan is always 2.52.8 times the length of the wing digit. The estimated wingspan for MJML K-1597 is 2.5 times the length of the wing digit, consistent with the pattern found in Rhamphorhynchus (see supplementary data).

The morphology highlighted above supports the identification of MJML K-1597 as an example of Rhamphorhynchus. In order to fully test this, a number of bivariate plots highlighting the ratios of the non-pterodactyloid wing were created (see supplementary data). For the majority of animals, the humerusMCIV complex is relatively conservative, with little variation occurring in the relative proportions. The only significant outliers are BMNHC PH000988 (Scaphognathus robustus, Bennett, 2014; Li et al., 2014) and all Campylognathoides specimens. BMNHC PH000988 has a relatively larger radius/ulna compared to the other specimens while Campylognathoides has a relatively larger humerus. MJML K-1597 can be distinguished from both these taxa using the morphology of the humerus. In contrast to the forearm, the ratio of the wing finger elements appears to be diagnostic with each data clustering into their respective genera. In each graph Rhamphorhynchus falls apart from all other taxa bar the morphologically distinct taxa Campylognathoides. MJML K-1597 consistently falls within the Rhamphorhynchus data range alongside the larger examples of the genus e.g. NHMUK 37787 and is identified as an example of the genus.

MJML K-1597 is identified as a Rhamphorhynchus, making it the first non-German pterosaur fossil that can be reliably assigned to the genus. There is however a single but significant morphological difference between MJML K-1597 and R. muensteri of potential taxonomic significance: the ratios between the proximodistal length of WP1 and WP2.

\section{Discussion}

As the second pterosaur genus to be erected, as well as the most numerous non-pterodactyloid pterosaur known (100 + specimens, Wellnhofer, 1975), the Tithonian ( 145-152 ma) Rhamphorhynchus has a long and complicated taxonomic history. While more detailed reviews can be found elsewhere (Wellnhofer, 1975; Bennett, 1995), the following summary provides an overview of the key points. The first specimen of Rhamphorhynchuswas a single skull and associated jaw from the Solnhofen Limestone, described by Goldfuss (1831). It was described as a new species of Ornithocephalus von Sömmerring, 1812 (a junior synonym of Pterodactylus) and named Ornithocephalus münsteri (the species name has since changed to muensteri according to ICZN Article 32.5.2). von Meyer (1847), following the description of several more 
specimens (e.g. Oken, 1819; Münster, 1839), recognised its generic distinctiveness and erected the genus Rhamphorhynchus. Between the Goldfuss (1831) description and Wellnhofer's (1975) review of Rhamphorhynchus' taxonomy, numerous species were erected, with 14 considered valid in 1975 (Wellnhofer, 1975; Bennett, 1995). Wellnhofer (1975) produced a detailed analysis of Rhamphorhynchus, describing all aspects of the animal from its osteology to its ontogeny. In the process he re-evaluated the taxonomy, reducing the species count to five: $R$. muensteri, $R$. longicaudus Münster, $1839, R$. gemmingi von Meyer, 1846, R. longiceps Woodward, 1902 and $R$. intermedius Koh, 1937. These species were retained based on the degree of fusion in the skeleton, maximum size and general morphology. Due to a lack of intermediately sized animals, they were not believed to be ontogenetic stages from a single species (Wellnhofer, 1975). Using Principal Component Analysis, size-frequency histograms, bivariate regressions and multivariate analyses, Bennett (1995) argued that the distinctions Wellnhofer (1975) thought represented distinct species were ontogenetic, with the various size groups representing year classes (Bennett, 1995, 1996). The lack of size intermediates was suggested to be due to the assemblage perhaps representing a record of seasonal mortality in a migratory species. Bennett (1995) therefore synonymised all pterosaurs identified as Rhamphorhynchus from the Kimmeridgian (152-157 ma), and Tithonian (157$145 \mathrm{ma}$ ) limestones of Germany into R. muensteri. Outside of Germany, several species of Rhamphorhynchus have been erected which Bennett (1995) did not examine in detail as he considered them beyond the scope of his analysis.

The above highlights the complex history of Rhamphorhynchus and shows how it has been subject to significant taxonomic debate over the past two centuries. With this in mind, we now consider the subtle but marked difference between MJML K-1597 and R. muensteri. As described above, WP1 in MJML K-1597 is $171 \mathrm{~mm}$ long and WP2 $175 \mathrm{~mm}$ long. This makes the ratio of WP1 divided by WP2 below 1 (WP1 96\% the length of WP2). This difference is small enough that it does not register on any of the bivariates however this study used data from 54 specimens of $R$. muensteri, representing all known age ranges (see supplementary data). Within this dataset there are no cases of the WP1 being shorter than the WP2. In a few specimens the bones are sub-equal in length (WP1 100-105\% the length of WP2) but in the majority of cases $(n=50)$ WP1 is $110-130 \%$ the length of WP2. This ratio has in fact previously been used as a part of the diagnosis for R. muensteri (Bennett, 1995). This precedence lends some support to using the WP1/WP2 ratio in MJML K-1597 as a taxonomic character. In order to test if this character reverses through either ontogeny or individual variation, the ratio from several pterodactyloid and non-pterodactyloid taxa was tabulated and compared (Table 2). With the exception of R. muensteri, Bellebrunnus (Hone et al., 2012), Sericipterus (which can be distinguished from MJML K-1597 based on its morphology) Peteinosaurus Wild, 1978 (which has a WP1 close to or equal to the length of WP2), Eudimorphodon and the highly derived Anurognathids (the phylogenetic placement of which is currently debatable; Kellner, 2003; Unwin, 2003; Bennett, 2007; Andres and Myers, 2013; Andres et al., 2014), non-pterodactyloid pterosaurs tend to 
have a WP1 shorter than their WP2. In pterodactyloids WP1 is always longer than WP2. As Table 2 shows, within a single taxon the WP1/WP2 ratio varies through ontogeny but the ratio only reverses in Eudimorphodon. While this raises the possibility that the ratio can shift ontogenetically in some pterosaurs, no such reversal is found in any other taxon. With an estimated wingspan of $1.7 \mathrm{~m}$ and all elements of the wing fully fused, MJML K-1597 is an adult animal of comparable size to the largest mature $R$. muensteri. The ontogenetic maturity and lack of ratio reversals in the 54 Rhamphorhynchus included in this study (see supplemental data) suggests that the ratio between WP1 and WP2 can be used as a diagnostic character in the case of most pterosaurs. While the difference in length in WP1 and WP2 in MJML K-1597 is merely 4\% (WP1/WP2 = 0.96363), it appears to be a distinct difference between MJML K-1597 and all other specimens of Rhamphorhynchus assigned to R. muensteri. However, one potential issue with using the wing to identify MJML K-1597 as Rhamphorhynchus is the recently erected Qinglongopterus and Bellebrunnus, both of which are morphologically similar to Rhamphorhynchus and thus raise questions about the validity of its diagnosis. 
Table 2: WP1/WP2 ratios of several basal and derived pterosaurs, showing that in most cases the ratios do not reverse through ontogeny or between related taxa. The only exception is Eudimorphodon. More comprehensive data on Rhamphorhynchus, Scaphognathus, Campylognathoides and Dorygnathus is included in the supplementary data.

\begin{tabular}{|c|c|c|c|c|}
\hline Taxon & Specimen number & WP1 (mm) & WP2 (mm) & WP1/WP2 \\
\hline Preondactylus & MSN 1770 & 35.5 & 39 & 0.910256 \\
\hline Campylognathoides & SMNKS?? & 185 & 209 & 0.885167 \\
\hline \multirow[t]{3}{*}{ Eudimorpodon } & MCSNB 6009 & 37.5 & 33 & 1.136364 \\
\hline & MCSNB 8950 & 34 & 35.3 & 0.963173 \\
\hline & MCSNB 1797 & 14.5 & 58.2 & 0.249141 \\
\hline \multirow[t]{3}{*}{ Dorygnathus } & SMNKS Nr. 81205 & 95.21 & 114.445 & 0.831928 \\
\hline & SMNKS Nr. 81206 & 63.68 & 70.97 & 0.897281 \\
\hline & SMNKS Nr. 81207 & 75.335 & 95.94 & 0.78523 \\
\hline \multirow[t]{8}{*}{ Rhamphorhynchus } & BSP munich 1934 I 36 & 50 & 46 & 1.086957 \\
\hline & \multicolumn{4}{|c|}{ Teyler museum, Haarlem (holland) } \\
\hline & Nr 6924 & 37 & 31.8 & 1.163522 \\
\hline & SMF R 4128 & 114.5 & 114 & 1.004386 \\
\hline & Meyer 1846 & 102.5 & 100 & 1.025 \\
\hline & SMNKS Nr. 52338 & 128.03 & 103.92 & 1.232005 \\
\hline & SMNKS Nr. 56980 & 89.495 & 85.77 & 1.04343 \\
\hline & MTM V 2008.33.1 & 98.8 & 92.2 & 1.071584 \\
\hline Bellebrunnus & BSP-1993-XVIII-2 & 27 & 23 & 1.173913 \\
\hline Scaphognathus & SMNKS Nr. 59395 & 34.89 & 38.4 & 0.908594 \\
\hline Arthurdactylus & SMNK 1132 PAL & 445 & 402 & 1.106965 \\
\hline Coloborhynchus & SMNK 1133 PAL & 620 & 566 & 1.095406 \\
\hline \multirow[t]{5}{*}{ Pterodactylus } & 10341 & 19.2 & 17.9 & 1.072626 \\
\hline & $1968 \mid 95$ & 44 & 40.5 & 1.08642 \\
\hline & na & 48.5 & 41 & 1.182927 \\
\hline & AS I 739 & 48.5 & 44.2 & 1.097285 \\
\hline & St 18184 & 58 & 57.5 & 1.008696 \\
\hline Haopterus & IVPP V11726 & 139.5 & 119 & 1.172269 \\
\hline Pterodaustro & na & 118.73 & 111.18 & 1.067908 \\
\hline Germanodactylus & 1892 IV 1 & 84 & 77.5 & 1.083871 \\
\hline Tapejaridae indet. & SMNK 3900 PAL & 298 & 186 & 1.602151 \\
\hline Sinopterus & IVPP V 13363 & 121 & 89.5 & 1.351955 \\
\hline Shenzhoupterus & HGM 41HIII-305A & 147 & 100 & 1.47 \\
\hline Eoazhdarcho & GMN-03-11-002 & 178 & 139 & 1.280576 \\
\hline Hauxiapterus & GMN-03-11-001 & 163 & 127 & 1.283465 \\
\hline
\end{tabular}




\section{Recent discoveries and the issues of diagnosing Rhamphorhynchus}

As highlighted by Hone et al. (2012) the recent erection of Bellebrunnus and Qinglongopterus, both taxa considered distinct but similar to Rhamphorhynchus, may call into question the definition of Rhamphorhynchus as presented above. A full re-evaluation of Rhamphorhynchus would require a level of analysis beyond the scope of this study; however in wing construction Qinglongopterus and Bellebrunnus are nearly identical to Rhamphorhynchus. Given that $R$. etchesi is defined as a Rhamphorhynchus based on the wing skeletal structure, in order to test if MJML K-1597 can be assigned to Rhamphorhynchus as a second species, the hypothesis that both genera are possibly synonymous with Rhamphorhynchus is evaluated.

The Oxfordian pterosaur Qinglongopterus from the Tiaojishan Formation (Lü et al., 2012) is defined on three characters: a relatively short skull that forms $28 \%$ of body length (skull + cervicals + dorsals + sacrals); short, slender pteroid with a knob-like distal expansion; and a prepubis with a relatively slender distal process. There are several problems with the validity of these characters. Lü et al. (2012) state that the skull being $28 \%$ of the body length is diagnostic as Rhamphorhynchus grows isometrically with respect to skull/body length, with a consistent value of $33 \%$. A bivariate analysis of the absolute values of Rhamphorhynchus skull/body length (see supplementary data) contradicts Lü et al. (2012). This graph has a $R^{2}$ value of 0.9826 , supporting a statistical relationship between Qinglongopterus and Rhamphorhynchus in terms of skull/body length. Removing Qinglongopterus from the analysis causes the $R^{2}$ value to rise slightly to 0.9874 but this shift is statistically insignificant with regards to the relationship in skull/body length between Qinglongopterus and Rhamphorhynchus. Here the skull of Rhamphorhynchus shows positive allometry relative to body length, ranging from $30 \%$ in flapplings to $40 \%$ large adults. This value is somewhat more variable in larger animals whose skulls can range from $36 \%$ to $40 \%$ of the body length. Qinglongopterus, the smallest animal included in the analysis with a skull $3 \mathrm{~mm}$ shorter than the smallest Rhamphorhynchus, appears on the graph where a Rhamphorhynchus of similar dimensions might be expected to fall. This suggests that rather than being a taxonomic character, the low skull/body length percentile is a product of the ontogenetic age of the specimen. The second character of the slender distal process of the prepubis is also problematic. While the distal process is clearly thinner than the anterior process (Lü et al., 2012), this is not unusual. Wellnhofer (1975) figures several prepubes which show variable degrees of thickness, including a specimen with a broad anterior process and a thin distal process. This character most likely varies with either age or sex and is of dubious diagnostic value. The final character, that of the thickness of the distal pteroid expansion, is difficult to judge based on the figures included in Lü et al. (2012). None of the characters given for Qinglongopterus are unambiguous autapomorphies and we suggest it is probable that Qinglongopterus is a junior synonym of Rhamphorhynchus.Lü et al. (2012) note that WP1 is very slightly shorter than WP2 in Qinglongopterus (WP1 is 99\% the length of WP2). Unfortunately the preservation of the distal epiphysis 
of the WP1 of Qinglongopterus is quite poor. Given how small the difference is between the phalanges $(0.3 \mathrm{~mm})$, we believe it is more likely that this difference is either a preservational artefact or represents the margin of error in the method of measurement methodology (Viscardi et al., 2012). Without access to the specimen to independently confirm the information presented by Lü et al. (2012), it is recommended that Qinglongopterus is referred to Rhamphorhynchussp. only. Regardless of the specific identification, Qinglongopterus remains a significant specimen as like MJML K-1597 it extends the biogeographic range of Rhamphorhynchuswell beyond Europe.

Bellebrunnus is defined by the following characters: 22 or less teeth; a long humerus 1.4 times the length of the femur; a femur lacking a femoral neck; no elongate caudal chevrons or zygapophyses; and a humerus with a straight shaft. Several of these characters are questionable. The majority of specimens of Rhamphorhynchus do have humeri less than 1.4 times the femoral length, with mature animals approaching but not achieving 1.4 (Hone et al., 2012), however exemplar 18 of Wellnhofer (1975) is a 'flappling' with a humerus comparable in size to Bellebrunnus and a humerus/femur ratio of 1.42. The characters of number of teeth, shaft straightness and the lack of a femoral neck are also problematic. While there are 21 teeth visible, this is possibly a minimum rather than a maximum number and other teeth may be covered by bone or missing from the specimen. Given the severely crushed nature of the skull it is difficult to determine using published figures if more teeth may have been present in the living animal. While the femur does lack a distinct femoral neck, several specimens figured in Wellnhofer (1975) show that the femoral neck may develop with age, again making this a difficult character to use as an autapomorphy. The straightness of the humeral shaft is also difficult to use taxonomically as several rhamphorhynchines (Wellnhofer, 1975; Lü et al., 2012) have shafts which appear straight and determining the straightness of a crushed specimen can be problematic. Ultimately the dubious nature of these features is due to the lack of an in-depth study into the way Rhamphorhynchus changes through ontogeny. For now, we consider Bellebrunnus to be sufficiently similar to Rhamphorhynchus to be considered congeneric based on the current diagnosis for the genus. There are however two characters of Bellebrunnus which make it possible it is not conspecific with $R$. muensteri: the lack of elongate caudal supports on the vertebrae and the anteriorly curving WP4.

The above opinions suggest that Bennett's (1995) diagnosis of Rhamphorhynchus can be used to generically identify an associated wing. However it is important to note that these opinions are not intended to be a full revision of either Qinglongopterus or Bellebrunnus. Such a revision is beyond the scope of this paper. Rather, they serve to highlight that, within the scope of the current diagnosis, Qinglongopterus and Bellebrunnus are similar enough to Rhamphorhynchus to be considered junior synonyms. Therefore we do not believe either taxon affects the diagnosis of MJML K-1597. Ultimately, a re-evaluation of Rhamphorhynchus is needed to develop a more robust diagnosis (see below). 


\section{Conclusions}

MJML K-1597 is placed in the new species R. etchesi. Unfortunately MJML K-1597 is currently the only rhamphorhynchine fossil from the Late Jurassic of the UK with an associated WP1 and WP2. While wing phalanges are the most common pterosaur element from the Oxfordian and Kimmeridgian of the UK, these are all isolated. Most can be diagnosed as rhamphorhynchine but any higher taxonomic placement is problematic. The rhamphorhynchine material from MJML is likely to belong to Rhamphorhynchus based on its association with MJML K-1597 but which species is currently unknown. A more in-depth evaluation is currently in progress which may find more diagnosable material but until it is complete, the MJML K rhamphorhynchine material is identified here as Rhamphorhynchussp.

As mentioned above, the establishment of $R$. etchesi highlights the need for an in-depth re-evaluation of the taxonomy of $R$. muensteri. In particular, specimens from outside the Solnhofen Limestone formation (e.g. those collected from the Nusplingen Limestone Formation) would benefit from further examination. The diagnosis of $R$. muensteri also needs consideration in light of the rapid expansion of pterosaur research since the mid-1990s. It is recommended that Rhamphorhynchus be re-evaluated in order to provide a stronger diagnosis for the genus, which may either permanently separate it from Qinglongopterus and Bellebrunnus, or allow both to be properly synonymised with it. Like its contemporary Scaphognathus (Bennett, 2014), Rhamphorhynchus appears to have been far more geographically wideranging than merely Europe. With its positive identification in the Kimmeridgian of the UK and the potential for its occurrence in China, it appears to have been a cosmopolitan genus across Eurasia, making it one of the most widespread Jurassic pterosaur genera known.

\section{Acknowledgements}

The authors would like to thank the Palaeontological Association for providing travel funds; Mr. Steve Etches for collection access and for providing several of the figures included in this manuscript; and Mr. Steven Vidovic for his extensive advice on analysing the data collected. The authors would like to express their gratitude towards Dr. Edina Prondvai and Dr. Brian Andres for their reviews and extremely helpful comments. Dr. Prondvai is further thanked for her detailed discussion on the statistical side of this study. Finally, thanks are given to Dr. Ross Elgin for the use of morphometric data from his doctoral thesis in Table 2. 